DOI 10.37882/2500-3682.2020.12.21

\title{
ГЕНДЕРНЫЕ РАЗЛИЧИЯ В ИНДИВИДУАЛЬНЫХ ЦЕННОСТЯХ РОССИЙСКОЙ МОЛОДЕЖИ
}

\section{GENDER DIFFERENCES IN THE INDIVIDUAL VALUES OF RUSSIAN YOUTH \\ P. Magomedov \\ G. Chanakaev}

Summary: The article presents the results of an empirical study of gender differences in individual values of Russian youth, obtained on an extensive sample of subjects represented by youth from three Russian regions. Differences in the individual values of boys and girls have been revealed, which indicate a more pronounced social orientation of girls in comparison with boys.

Keywords: individual values, gender differences, socially oriented values, individualistically oriented values.
Магомедов Пахрудин Шабанович

к.nсх.н., доцент, Дагестанский государственный университет, филиал в г. Кизляре

pakhru@mail.ru

Чанакаев Герай Магомедзагидович

Соискатель, Дагестанский государственный педагогический университет insait6@yandex.ru

Аннотация: В статье представлены результаты эмпирического исследования гендерных различий в индивидуальных ценностях российской молодежи, полученные на обширной выборке испытуемых, представленной молодежью трех российских регионов. Выявлены различия в индивидуальных ценностях юношей и девушек, которые свидетельствуют о более выраженной социальной ориентированности девушек по сравнению с юношами.

Ключевые слова: индивидуальные ценности, гендерные различия, социально ориентированные ценности, индивидуалистически ориентированные ценности.

ет половую дифференциацию в социальных ролях анатомо-физиологическими различиями между мужским и женским полами. Исходя из этого, возникновение психологических различий между ними считается неизбежным, а культуре приписывается лишь роль посредника в их осмыслении и своеобразном проявлении.

Социокультурная парадигма, исходная для нас, объясняет указанные различия влиянием условий социализации, культурной среды, которые предписывают мужские и женские роли при их освоении детьми, т.е. считает, что социокультурные факторы предопределяют обучение традиционно принятым ролям женщин и мужчин, что и приводит к возникновению психологических различий между ними. Усвоенные в процессе социализации ценности и культурные нормы находят свою репрезентацию в индивидуальных ценностях, определяющих мотивацию и поведение личности. Исходя из этого, мы предполагали, что система ценностей юношей и девушек будет отличаться: для первых более значимыми по сравнению с девушками являются индивидуально ориентированные ценности, а девушки более привержены консервативным ценностям.

Данное эмпирическое исследование проходило в 2017 году. Выборка исследования включала в себя 296 юношей 260 девушек в возрасте от 15 до 23 лет, из них 96 человек представляли старшеклассников и студентов г. Санкт-Петербурга, 143 - г. Грозного, 317 - г. Махачкалы, всего 556 человек.

Как известно, социобиологическая модель объясня- 
Эмпирические данные были получены с применением методики Ш. Шварца для изучения ценностей личности, часть II: Профиль личности [4].

В своей концепции Ш. Шварц и В. Билски рассматривают индивидуальные ценности как мотивационные цели, руководящие принципы жизни, как некие (часто неосознаваемые) критерии выбора и оценки своих поступков, оценки других людей и событий [5]. В теоретической модели Ш. Шварца выделено 10 типов ценностей, каждый из которых включает в себя ряд близких друг другу мотивационных целей. 10 типов ценностей объединены в группы «ценностей высшего порядка», которые образуют две биполярные оси измерения. На первой оси измерения расположены открытость изменениям (самостоятельность, стимуляция, гедонизм)в противоположность сохранению (безопасность, конформность, традиция); на второй - самоутверждение (власть, достижения) - в противоположность самопреодолению (универсализм, доброта). Типы ценностей также разделены на две пары «метаценностей»: 1) ценности индивидуалистической ориентации - социальной ориентации; 2) ценности самозащиты - роста и развития.

Ниже приведены полученные эмпирические данные и результаты их первичной и статистической обработки.

В таблице 1 даны описательные статистики ценностей девушек и юношей.

На рисунках 1 и 2 представлены диаграммы рангов значимости ценностей для девушек и юношей. Сравнение иерархий ценностей, а также данные кластерного анализа ценностей показывают наличие существенных различий в иерархиях ценностей между юношами и девушками.

Как следует из данных на рисунках 1 и 2, у девушек иерархию ценностей возглавляет социально ориентированный ценностный тип доброта (доброжелательность), у юношей - самостоятельность - индивидуально ориентированный ценностный тип, который у девушек занимает второе место в иерархии. В целом, доминирующая тройка ценностей юношей и девушек одинакова по составу, но различается по иерархии, отражая большую индивидуалистическую ориентированность юношей.

Что касается ценностей среднего уровня, то стимуляция предпочтительнее для юношей по сравнению с девушками, более приверженными гедонизму, т.е. юноши активнее девушек. Ценностный тип безопасность, относящийся к консервативным ценностям, для девушек более значим по сравнению с конформностью. В иерархии ценностей юношей конформность вытесняет безопасность назад. Таким образом, эти данные под- тверждают культурные представления о гендерных ролях. Вместе с тем для обеих групп отвергаемыми являются ценностные типы власть и достижения, связанные с самоутверждением, что свидетельствует о социальной пассивности молодежи в целом.

Ниже представлены результаты кластерного анализа ценностей по группам девушек и юношей. Как следует из анализа дендограмм на рисунках 3 и 4, структура кластеров ценностей девушек и юношей различается.

Результаты кластерного анализа ценностей девушек представлены в таблице 2 и на рисунке 3. Аналогичные данные для юношей содержатся в таблице 3 и на рисунке 4.

Сравнение кластеров ценностей на дендограммах (рисунки 3 и 4) показывает, что их структура существенно отличается друг от друга. Ценности девушек объединены в три кластера с вытеснением ценностного типа власть. Первый кластер включает в себя доминирующие ценности доброта, универсализм и самостоятельность, второй - ценности среднего уровня конформность, безопасность и традиция, третий кластер - менее значимые индивидуалистические ценности стимуляция, гедонизм и достижения.

Отметим, что ценности первого кластера девушек выражают большую открытость изменениям, по сравнению со вторым кластером, где объединены только консервативные ценности. Третий блок включает в себя как ценности открытости изменениям, так и ценности блока самоутверждения, которые являются отвергаемыми для молодежи.

У юношей структура кластеров несколько отличается от предыдущей, она не имеет четкого разделения на три кластера (рисунок 4). При этом кластер консервативных ценностей (конформность, безопасность и традиция) у юношей и девушек полностью совпадает. Что касается первого кластера ценностей юношей, он состоит их четырех типов ценностей (по два из блока открытости изменениям и самопреодоления), в отличие от аналогичного кластера девушек, в котором преобладают ценности самопреодоления (рисунок 3). У юношей ценности, не вошедшие в первые два кластера (достижения, гедонизм, власть), последовательно по одному примыкают к агломерации двух вышеназванных кластеров ценностей.

Таким образом, иерархия ценностей юношей более противоречива по сравнению с таковой у девушек, при этом юноши более индивидуалистически ориентированы по сравнению с девушками. Последние отличаются большей социальной ориентированностью, ценности доброта и безопасность занимают более высокое место 
Таблица 1.

Описательные статистики ценностей девушек и юношей

\begin{tabular}{|c|c|c|c|c|}
\hline Типы ценностей по Ш. Шварцу & $\begin{array}{c}\text { 0-девушки } \\
\text { 1-юноши }\end{array}$ & N & Среднее значение & Стандарт. отклонение \\
\hline \multirow[t]{2}{*}{ КОНФОРМНОСТЬ } & 0 & 260 & 2,2930 & 89001 \\
\hline & 1 & 296 & 2,3082 &, 82942 \\
\hline \multirow[t]{2}{*}{ ТРАДИЦИЯ } & 0 & 260 & 2,3509 & 1,01261 \\
\hline & 1 & 296 & 2,3742 & 93513, \\
\hline \multirow[t]{2}{*}{ ДОБРОТА } & 0 & 260 & 2,7700 &, 84966 \\
\hline & 1 & 296 & 2,6526 & 76610 \\
\hline \multirow[t]{2}{*}{ УНИВЕРСАЛИЗМ } & 0 & 260 & 2,6929 & ,77038 \\
\hline & 1 & 296 & 2,6582 & ,75537 \\
\hline \multirow[t]{2}{*}{ САМОСТОЯТЕЛЬНОСТЬ } & 0 & 260 & 2,7073 & ,77419 \\
\hline & 1 & 296 & 2,7283 & ,70427 \\
\hline \multirow[t]{2}{*}{ СТИмУлЯция } & 0 & 260 & 2,3857 & ,99634 \\
\hline & 1 & 296 & 2,4442 & 89740 \\
\hline \multirow[t]{2}{*}{ ГЕДОНИЗМ } & 0 & 260 & 2,4625 & 1,19193 \\
\hline & 1 & 296 & 2,4328 & 1,07412 \\
\hline \multirow[t]{2}{*}{ ДОСТИЖЕНИЯ } & 0 & 260 & 2,2376 & ,99239 \\
\hline & 1 & 296 & 2,2763 & 88907 \\
\hline \multirow[t]{2}{*}{ ВЛАСТЬ } & 0 & 260 & 1,1164 & 1,25022 \\
\hline & 1 & 296 & 1,5529 & 1,05089 \\
\hline \multirow[t]{2}{*}{ БЕЗОПАСНОСТЬ } & 0 & 260 & 2,3263 &, 81152 \\
\hline & 1 & 296 & 2,2709 & ,87256 \\
\hline
\end{tabular}

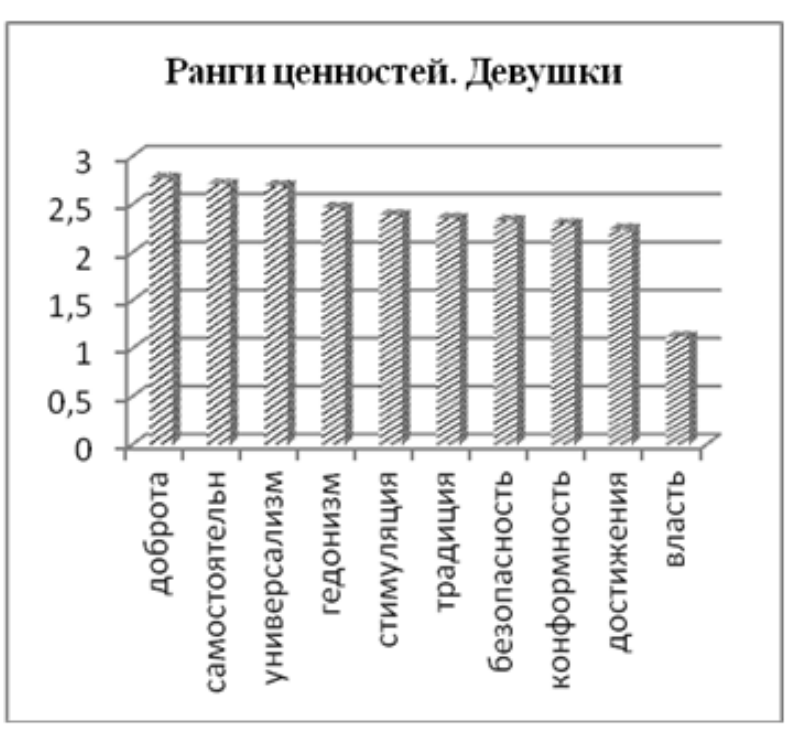

Рис. 1. Ранги ценностей девушек

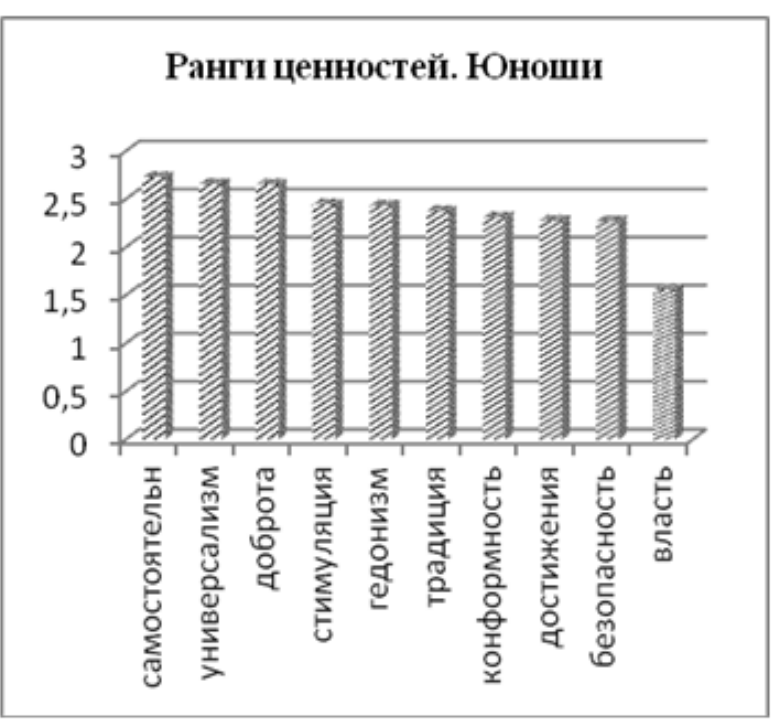

Рис. 2. Ранги ценностей юношей

Серия: Познание №12 декабрь 2020 г. 
Таблица 2.

Кластерный анализ ценностей девушек

\begin{tabular}{|c|c|c|c|c|c|c|}
\hline \multirow{2}{*}{ Этап } & \multicolumn{2}{|c|}{ Объединенный кластер } & \multirow{2}{*}{ Коэффициенты } & \multicolumn{2}{|c|}{ Этап первого появления кластера } & \multirow{2}{*}{$\begin{array}{c}\text { Следующий } \\
\text { этап }\end{array}$} \\
\hline & Кластер 1 & Кластер 2 & & Кластер 1 & Кластер 2 & \\
\hline 1 & 3 & 4 & 218,498 & 0 & 0 & 4 \\
\hline 2 & 1 & 10 & 280,585 & 0 & 0 & 3 \\
\hline 3 & 1 & 2 & 367,704 & 2 & 0 & 5 \\
\hline 4 & 3 & 5 & 397,163 & 1 & 0 & 5 \\
\hline 5 & 1 & 3 & 460,429 & 3 & 4 & 8 \\
\hline 6 & 6 & 7 & 469,889 & 0 & 0 & 7 \\
\hline 7 & 6 & 8 & 553,410 & 6 & 0 & 8 \\
\hline 8 & 1 & 6 & 663,723 & 5 & 7 & 9 \\
\hline 9 & 1 & 9 & 1470,471 & 8 & 0 & 0 \\
\hline
\end{tabular}

Дендрограмма с использованием метода межгрупповых связей

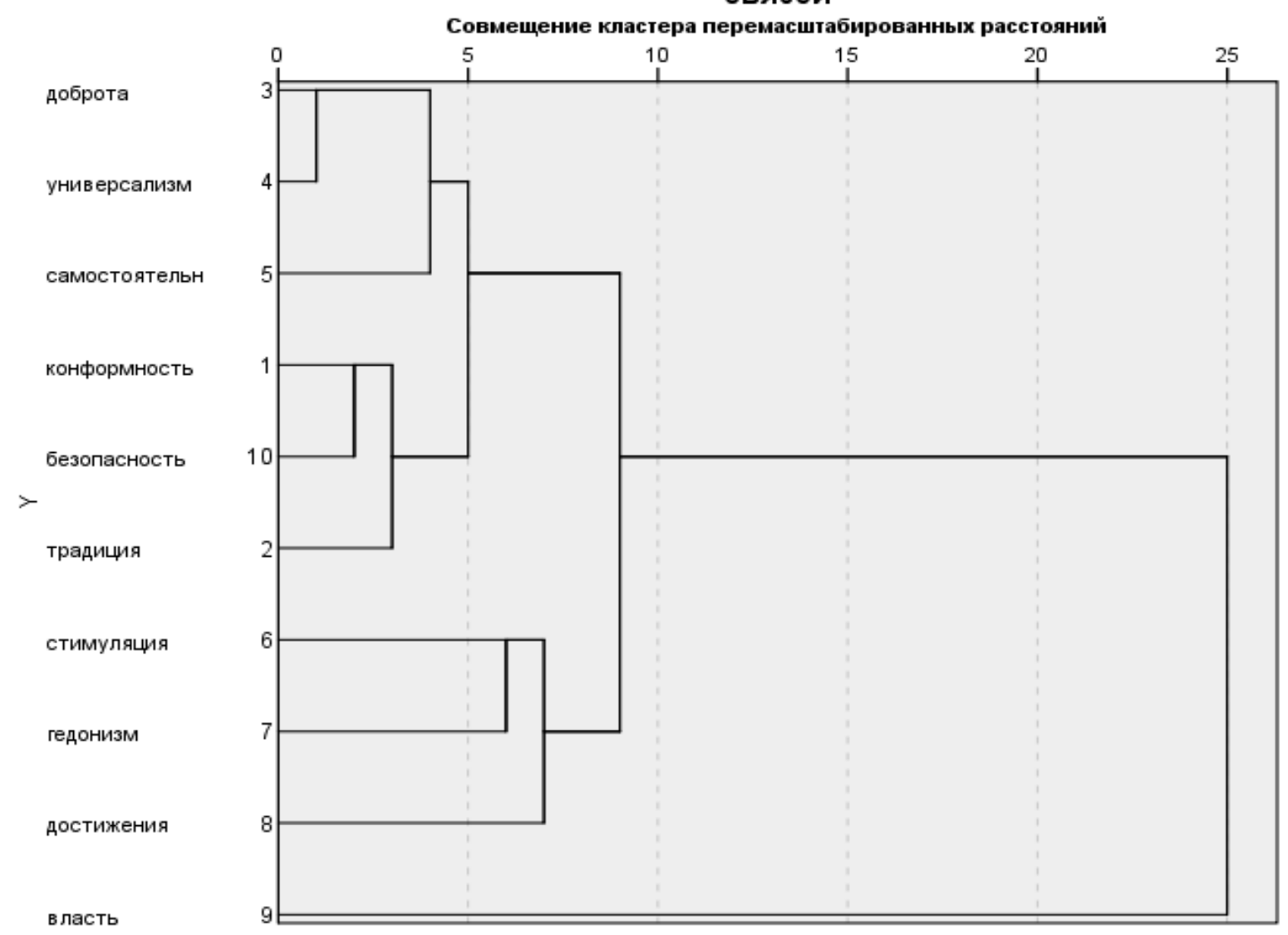

Рис. 3. Кластеры ценностей девушек 
Таблица 3.

Кластерный анализ ценностей юношей

Порядок агломерации (кластеров). Метод средней связи (между группами). Мера связи: квадрат расстояния Евклида

\begin{tabular}{|c|c|c|c|c|c|c|}
\hline \multirow{2}{*}{ Этап } & \multicolumn{2}{|c|}{ Объединенный кластер } & \multirow{2}{*}{$\begin{array}{c}\text { Коэффици- } \\
\text { енты }\end{array}$} & \multicolumn{2}{|c|}{$\begin{array}{c}\text { Этап первого появления } \\
\text { кластера }\end{array}$} & \multirow{2}{*}{$\begin{array}{c}\text { Следующий } \\
\text { этап }\end{array}$} \\
\hline & Кластер 1 & Кластер 2 & & Кластер 1 & Кластер 2 & \\
\hline 1 & 13 & 14 & 121,677 & 0 & 0 & 3 \\
\hline 2 & 11 & 20 & 145,030 & 0 & 0 & 4 \\
\hline 3 & 13 & 15 & 161,472 & 1 & 0 & 5 \\
\hline 4 & 11 & 12 & 170,403 & 2 & 0 & 6 \\
\hline 5 & 13 & 16 & 207,964 & 3 & 0 & 6 \\
\hline 6 & 11 & 13 & 228,595 & 4 & 5 & 7 \\
\hline 7 & 11 & 18 & 246,712 & 6 & 0 & 8 \\
\hline 8 & 11 & 17 & 339,942 & 7 & 0 & 9 \\
\hline 9 & 11 & 19 & 503,878 & 8 & 0 & 0 \\
\hline
\end{tabular}

Дендрограмма с использованием метода межгрупповых связей

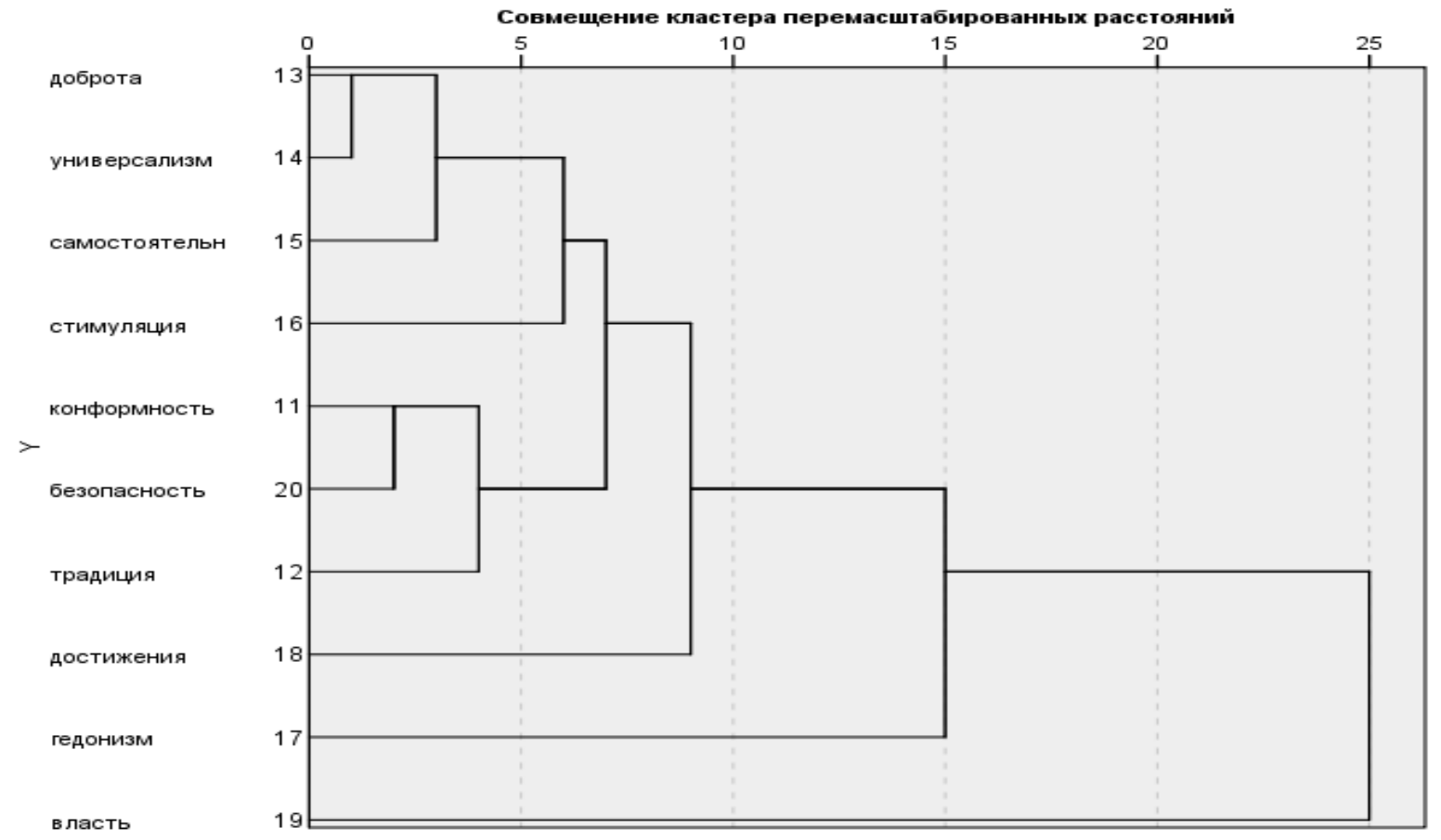

Рис. 4. Кластеры ценностей юношей 
в иерархии их ценностей.

Так как этнокультурная неоднородность выборки нивелирует имеющиеся различия, в отличие от результатов данного исследования, проведенного на этнически смешанной выборке, вероятно, в рамках отдельных этнических групп гендерные различия будет выглядеть иначе. На это указывают данные, полученные на выборке дагестанской молодежи [6]. В этой связи представляется важным проанализировать гендерные различия в ценностях с учетом этнокультурного своеобразия разных групп молодежи.

\section{Выводы}

1. Иерархии ценностей юношей и девушек соответствуют культурным нормам, предписывающим большую социальную активность юношам в отли- чие от девушек. Это проявляется в доминировании самостоятельности в иерархии ценностей юношей, тогда как для девушек наиболее значимый ценностный тип - доброта (доброжелательность).

2. Ценности самоутверждения в иерархии ценностей молодежи являются отвергаемыми, что указывает на недостаточную поддержку в российской культуре индивидуализма, а также на коллективистский характер культуры.

3. Консервативные ценности малозначимы для российской молодежи, вместе с тем юноши более открыты изменениям, а девушки более консервативны, что соответствует гендерным ролям и подтверждает социокультурную обусловленность различий в ценностях между юношами и девушками.

\section{ЛИТЕРАТУРА}

1. Клецина И.С. Развитие гендерных исследований в отечественной психологии: итоги и перспективы // Педагогика. Психология. Философия. 2017. №3 (07). URL: https://cyberleninka.ru/article/n/razvitie-gendernyh-issledovaniy-v-otechestvennoy-psihologii-itogi-i-perspektivy (дата 0бращения: 05.10.2020).

2. Zosuls KM., Miller CF., Ruble DN., Martin CL., Fabes RA. Gender Development Research in Sex Roles: Historical Trends and Future Directions. Sex Roles. 2011. Jun; 64(11-12):826-842. doi: 10.1007/s11199-010-9902-3. PMID: 21747580; PMCID: PMC3131694.

3. Бэрон Р., Ричардсон Д. Агрессия. СПб., 1997; Bussey К, Bandura A. Social cognitive theory of gender development and differentiation. Psychological Review. 1999;106:676-713. doi: 10.1037/0033-295X.106.4.676; Fabes RA., Eisenberg N. Unpublished manuscript. Arizona State University; 1996. Age and gender differences in prosocial behavior: A metaanalytic examination.

4. Карандашев В.Н. Методика Шварца для изучения ценностей личности: концепция и методическое руководство. - СПб.: Речь, 2004. - 70 с.

5. Schwartz S., Bilsky W. Toward a theory of the universal content and structure of values: Extensions and cross-cultural replications. Schwartz, Shalom H.; Bilsky, Wolfgang // Journal of Personality and Social Psychology, Vol 58(5), May 1990, 878-891. http://dx.doi.org/10.1037/0022-3514.58.5.878.

6. Магомедов П.Ш., Магомедова А.П., Шуруха Т.А. Гендерные различия в индивидуальных ценностях дагестанской молодежи // Известия Дагестанского государственного педагогического университета. Сер. «Психолого-педагогические науки». - Т.11. № 2, 2017. С. 15-21.

(c) Магомедов Пахрудин Шабанович (pakhru@mail.ru), Чанакаев Герай Магомедзагидович (insait6@yandex.ru). 